\title{
BISIKAN DARI BALIK LAYAR: NETNOGRAFI STRATEGI BISNIS BERORIENTASI PASAR
}

\author{
Edi Purwanto \\ Manajemen, Universitas Bunda Mulia, Jakarta. \\ Alamat surel: epurwanto@bundamulia.ac.id \\ John J.O.I. Ihalauw \\ Manajemen, Universitas Bunda Mulia, Jakarta. \\ Alamat surel: ihalauw@bundamulia.ac.id
}

\begin{abstract}
Netnography is an interpretative approach to study consumer behavior from different cultures and communities in the cyberspace or Internet. The approach was also called as a "digital ethnography" or "virtual ethnography". As a marketing research technique, "netnography" uses the information sources published in the online forums. This research uses the reviews on zomato.com as a source of data to assess the market orientation development in business practice, especially at Restaurant X. The result of netnography analysis indicates that customer orientation, competitor orientation, interfunctional coordination and long-term focus are the dimensions of market orientation and should be developed for customer satisfaction and loyalty leading forward to the business performance.
\end{abstract}

Keywords: netnography, market orientation.

\section{Pendahuluan}

Seringkali orang mengartikan "komunitas maya" (virtual communities) sebagai yang kurang "nyata" dibandingkan dengan komunitas yang bersifat fisik (Jones 1995, Kozinets, 2002). Namun menurut Kozinets (1998) kelompok-kelompok sosial tersebut memiliki keberadaan yang "nyata" karena kelompok-kelompok sosial tersebut sejatinya memiliki anggota kelompok yang nyata, dan membawa dampak-dampak pada banyak aspek perilaku, termasuk perilaku konsumen (Kozinets, 2002, Muniz and O’Guinn 2001).

Kozinets (2010) menjelaskan apa sebenarnya budaya-budaya dan komunitaskomunitas daring (online), dan mengapa semua itu merupakan topik yang penting bagi para ahli ilmu sosial. Sejak awal, lingkungan sosial daring dipandang dengan kecurigaan dan sinisme, dipandang sebagai impersonal, dingin, dan interaksi-interaksi yang mematikan kehidupan sosial yang nyata (Kozinets, 2010:23). Namun Kozinets (1998) berargumen beberapa ahli menjelaskan bahwa budaya dan komunitas tercipta melalui komunikasi, dan bahwa komunitas maya ini mendemonstrasikan lebih dari sekedar transmisi informasi. Namun "seremoni suci tersebut menarik orang-orang untuk bergabung dalam persekutuan dan kebersamaan" (Carey 1989:18), sehingga komunitas maya dapat dilihat sebagai komponen-komponen masyarakat baru yang hidup.

Komunitas maya yang dipelajari dengan pendekatan netnografi dalam penelitian ini adalah komunitas pelanggan restoran $\mathrm{X}$ yang meninggalkan komentar mereka pada zomato.com. Restoran X sendiri merupakan bisnis lokal yang mulai dibangun di Jakarta dan saat ini, seperti yang tercatat dalam zomato.com, memiliki 7 (tujuh) gerai di DKI Jakarta: (1) Restoran X di Ruko Crown Golf, Blok D, Bukit Golf Mediterania, Jl. Marina Indah Raya, Pantai Indah Kapuk, Jakarta, (2) Restoran X di Kota Kasablanka, Lantai Lower Ground, Jl. Casablanca Raya, Tebet, Jakarta, (3) Restoran X di Ruko Green Lake, Jl. Danau Sunter, Sunter, Jakarta, (4) Restoran X di Grand Indonesia Mall, Lantai 3A, West Mall, Jl. MH Thamrin, Thamrin, Jakarta, (5) Restoran X di Central Park, Lantai 3, Jl. Letjen S. Parman, Tanjung Duren, Jakarta, (6) Restoran X di Mall Taman Anggrek, Lantai 4, Jl. Tanjung Duren Timur 2, Tanjung Duren, Jakarta, dan (7) Restoran X di Puri Indah Mall Expansion, 
Lantai 1, Jl. Puri Indah Raya, Puri Indah, Jakarta.

Hal-hal yang belum diketahui dalam penelitian ini adalah apakah Restoran X telah melakukan strategi berorientasi pasar dalam meningkatkan kinerja perusahaannya. Pengembangan orientasi pasar sebagai pangkalan bisnis menjadi sangat penting dalam konteks persaingan bisnis. Oleh sebab itu persoalan-persoalan penelitian ini adalah (1) Sejauh apa perusahaan telah mengadopsi orientasi pasar sebagai pangkalan strategi bisnis yang diperlukan oleh perusahaan? (2) Dimensi dari orientasi pasar yang mana saja yang perlu ditingkatkan untuk menaikkan kinerja?

\section{Orientasi pasar}

Orientasi pasar telah menjadi salah satu konsep yang sangat penting dalam penelitian (Kara et. al., 2005). Perreault and McCarthy (2002) menjelaskan bahwa orientasi pasar terdiri dari (1) customer orientation and targeting; (2) profit orientation; dan (3) integrated marketing organization, yang mana integrasi usaha dari semua area organisasi adalah untuk tujuan memenuhi kebutuhan dan keinginan pelanggan. Dalam penelitian Kohli dan Jaworski (1990) orientasi pasar terdiri dari serangkaian perilaku dan proses keorganisasian yang berhubungan dengan (1) market intelligence generation; (2) market intelligence dissemination; dan (3) responsiveness to such intelligence across departments. Menurut Carbonell dan Escudero (2010) intelligence generation mengacu pada keluasan informasi primer maupun sekunder yang perusahaan kumpulkan dari para pemangku kepentingan (stakeholders) perusahaan, misalnya para pesaing, pemasok, perantara) dan kekuatan-kekuatan pasar, seperti faktor-faktor sosial, budaya, regulasi dan ekonomi makro. Kemudian intelligence dissemination mengacu pada tingkat bagaimana informasi tersebut didistribusikan, disebarluaskan dan didiskusikan antar semua fungsi manajemen yang berhubungan dalam artian formal maupun informal. 
Tabel 1 - Instrumen Pengukuran Orientasi Pasar

\begin{tabular}{|c|c|}
\hline \multicolumn{2}{|c|}{ Customer Orientation (CSO) } \\
\hline CSO1 & Informasi mengenai kebutuhan dan permintaan pelanggan dikumpulkan secara teratur \\
\hline $\mathrm{CSO} 2$ & Tujuan dan kebijakan perusahaan kami diarahkan untuk menciptakan kepuasan pelanggan. \\
\hline $\mathrm{CSO} 3$ & $\begin{array}{l}\text { Tingkat kepuasan pelanggan dievaluasi secara teratur untuk dapat memperbaiki permasalahan } \\
\text { apabila diperlukan. }\end{array}$ \\
\hline $\mathrm{CSO} 4$ & $\begin{array}{l}\text { Kami berusaha dengan giat untuk membangun keakraban dengan para pelanggan utama dan } \\
\text { kelompok-kelompok pelanggan lainnya. }\end{array}$ \\
\hline CSO5 & $\begin{array}{l}\text { Kami mengenali adanya perbedaan kelompok atau segmen dalam pasar dengan jenis kebutuhan } \\
\text { yang berbeda namun kami dapat menyesuaikan penawaran kami menurut kebutuhan mereka. }\end{array}$ \\
\hline \multicolumn{2}{|c|}{ Competitor Orientation (CMO) } \\
\hline CMO1 & Informasi mengenai aktivitas pesaing dikumpulkan secara teratur. \\
\hline $\mathrm{CMO} 2$ & Kami membandingkan diri kami secara teratur terhadap pesaing utama. \\
\hline CMO3 & $\begin{array}{l}\text { Kami menanggapi dengan cepat terhadap tindakan-tindakan yang dilakukan oleh pesaing } \\
\text { utama. }\end{array}$ \\
\hline CMO4 & $\begin{array}{l}\text { Kami menitikberatkan pada diferensiasi/keunikan yang kami miliki sebagai faktor penting bagi } \\
\text { para pelanggan }\end{array}$ \\
\hline \multicolumn{2}{|c|}{ Long-Term Perspectives (LTP) } \\
\hline LTP1 & $\begin{array}{l}\text { Kami lebih memprioritaskan untuk mencapai keunggulan pangsa pasar jangka panjang } \\
\text { ketimbang laba jangka pendek. }\end{array}$ \\
\hline LTP2 & $\begin{array}{l}\text { Kami lebih menitik beratkan pada peningkatan kinerja pasar kami ketimbang meningkatkan } \\
\text { efisiensi internal }\end{array}$ \\
\hline LTP3 & $\begin{array}{l}\text { Pengambilan keputusan ditentukan berdasarkan pertimbangan jangka panjang ketimbang } \\
\text { manfaat jangka pendek. }\end{array}$ \\
\hline \multicolumn{2}{|c|}{ Interfuctional Coordination (IC) } \\
\hline IC1 & Informasi tentang pelanggan disebarluaskan melalui komunikasi ke seluruh organisasi. \\
\hline $\mathrm{IC} 2$ & $\begin{array}{l}\text { Masing-masing departemen dalam organisasi bekerja bersama dengan efektif untuk melayani } \\
\text { kebutuhan pelanggan. }\end{array}$ \\
\hline IC3 & $\begin{array}{l}\text { Ketegangan dan persaingan antar departemen tidak boleh menghalangi proses pelayanan } \\
\text { pelanggan secara efektif. }\end{array}$ \\
\hline IC4 & $\begin{array}{l}\text { Organisasi kami fleksibel untuk mengejar peluang secara efektif ketimbang dibatasi secara } \\
\text { hirarki/birokratis. }\end{array}$ \\
\hline \multicolumn{2}{|c|}{ Organizational Culture (OC) } \\
\hline OC1 & $\begin{array}{l}\text { Semua karyawan menyadari peran mereka dalam membantu untuk menciptakan kepuasan } \\
\text { pelanggan. }\end{array}$ \\
\hline $\mathrm{OC} 2$ & $\begin{array}{l}\text { Struktur imbalan/penghargaan karyawan berkaitan erat dengan kinerja pasar eksternal dan } \\
\text { kepuasan pelanggan. }\end{array}$ \\
\hline OC3 & $\begin{array}{l}\text { Para pimpinan senior di seluruh area fungsional memberikan prioritas utama untuk } \\
\text { menciptakan kepuasan pelanggan. }\end{array}$ \\
\hline $\mathrm{OC} 4$ & $\begin{array}{l}\text { Rapat-rapat yang dilakukan oleh para pimpinan senior sangat memprioritaskan untuk } \\
\text { membahas hal-hal yang dapat memengaruhi kepuasan pelanggan. }\end{array}$ \\
\hline
\end{tabular}

Matsuno et al. (2000) mengembangkan skala yang dipakai untuk mengukur orientasi pasar seperti berikut ini: (1) intelligence generation diukur dengan lima item: unit informasi dalam bisnis secara periodik harus dikumpulkan untuk meningkatkan produk, kepuasan pelanggan, kebutuhan pemasok dan perantara, aktivitas para pesaing dan perubahan pasar dan lingkungan, (2) empat item untuk mengukur intelligence dissemination: informasi yang dikumpulkan disebarluaskan ke semua fungsi departemen, didokumentasikan, diteruskan dengan cepat ke semua fungsi departemen, dan didiskusikan di antara semua departemen, dan akhirnya (3) empat item untuk mengukur responsiveness: informasi yang telah dikumpulkan digunakan untuk menanggapi 
perubahan pada kebutuhan pelanggan, menelaah usaha-usaha pengembangan produk, menanggapi tindakan-tindakan pesaing dan menangangi keluhan-keluhan pelanggan.

Hooley et al. (2012) menunjukkan 5 dimensi dan konteks pemasaran dari orientasi pasar, yaitu (1) orientasi pada pelanggan, yaitu memahami pelanggan dengan sangat baik secara terus-menerus untuk menciptakan nilai tertinggi untuk mereka; (2) orientasi pada pesaing, yaitu kesadaran terhadap kapabilitas jangka pendek dan jangka panjang dari para pesaing; (3) koordinasi interfungsional, yang menunjuk pada penggunaan semua sumberdaya perusahaan dalam mencipta nilai untuk pelanggan sasaran; (4) budaya keorganisasian, yaitu penautan karyawan perusahaan dan perilaku manajerial dengan kepuasan pelanggan, dan (5) fokus jangka panjang yang menunjuk pada tujuan perusahaan.

Sejumlah penelitian terdahulu untuk orientasi pasar di antaranya ialah: Fang et al. (2014) menemukan bahwa orientasi pasar internal memfasilitasi pengembangan kemampuan pasar yang selanjutnya meningkatkan kinerja organisasi. Temuan tersebut juga menunjukkan kemampuan jaringan pelanggan sebagai perantara yang kuat antara orientasi pasar internal dengan kinerja perusahaan. O'Sullivan dan Butler (2009) menguji manfaat dari kebijakan perusahaan yang berusaha untuk meningkatkan orientasi pasar sebagai pendorong kinerja perusahaan, namun tidak menemukan keterhubungan tidak langsung antara orientasi pasar dengan kinerja perusahaan di perusahaan-perusahaan highvalue-added dalam perekonomian Irlandia. Pulendran et al. (2003) menyatakan perencanaan pemasaran berkualitas tinggi dapat memberikan manfaat kinerja sebagai anteseden orientasi pasar ketimbang sebagai kegiatan mandiri. Narver dan Slater (1990) menemukan pengaruh positif dan substansial orientasi pasar terhadap kemampulabaan, baik pada bisnis produk komoditi mau pun bukan komoditi. Julian (2013) menemukan tiga dimensi orientasi pasar (orientasi pada pelanggan, orientasi pada pesaing dan koordinasi antarfungsi) memiliki pengaruh signifikan terhadap kinerja pemasaran ekspor pada sektor manufaktur di Indonesia.

\section{Metode Netnografi}

Metode netnografi sering disebut juga online ethnography atau virtual ethnography dipopulerkan oleh Robert Kozinets pada tahun 1997 (Maulana, 2009). Kozinets (1998) berkata bahwa "netnografi adalah sebuah metode interpretatif yang secara spesifik meneliti perilaku konsumen dari berbagai budaya dan komunitas yang dihadirkan dalam dunia maya atau Internet." Kemudian Kozinets (1998) mendefinisikan netnografi sebagai hasil catatan tertulis dari penelitian budaya dan komunitas yang datang dari komunikasi-komunikasi daring, menggunakan media komputer, atau komunikasi berbasis Internet, di mana baik kerja lapangan (field work) dan catatan bersifat teks (textual account) secara metodologi menggunakan tradisi dan teknik antropologi budaya.

Menurut Kozinets (2002) "netnografi" dapat disebut juga etnografi pada Internet, atau dari "Inter[net] dan et[nografi]", yang merupakan metodologi penelitian kualitatif baru yang mengadaptasi teknik penelitian etnografi untuk meneliti berbagai budaya dan komunitas yang dikumpulkan melalui komunikasi-komunikasi dengan menggunakan media komputer. Sebagai sebuah teknik riset pemasaran, "netnografi" menggunakan informasi yang terpublikasi dalam forum-forum daring. Ada juga yang menyebut netnografi sebagai "digital ethnography" atau "virtual ethnography" (Nguyen, 2013)

Netnografi merupakan komunikasi menggunakan komputer atau computermediated communications (CMC), yaitu komunikasi yang terjadi melalui komputer atau jaringan. CMC tersebut termasuk di dalamnya ialah forums, postings, instant message, email, chat-room, dan mobile text message (Kozinets, 2010). Jadi CMC merupakan sumber bagi para peneliti untuk 
mengumpulkan data etnografi mereka, data yang merepresentasikan fenomena budaya dan masyarakat.

Keunggulan dari metode netnografi ini adalah kecepatan dalam mengumpulkan informasi, berbiaya sangat rendah dibandingkan dengan teknik etnografi lainnya dan dianggap lebih alami dan tidak instruksif atau mengganggu keaslian dari apa yang terjadi atau bahasan yang dipercakapkan. Kelemahannya terletak seberapa ahli seorang etnografer dalam menginterpretasikan informasi yang diperoleh dan identitas seseorang dalam alam maya seringkali tidak menggambarkan keadaan sebenarnya (Maulana, 2009).

Nguyen (2013) memberikan beberapa langkah dalam melakukan riset netnografi; (1) langkah pertama adalah menetapkan rumusan masalah, situs-situs sosial atau topik-topik untuk diteliti, (2) langkah kedua adalah identifikasi dan pemilihan komunitas yang akan diteliti, (3) langkah ketiga adalah pengumpulan data, (4) langkah keempat adalah analisis data dan interpretasi berbagai temuan secara terus-menerus hingga titik jenuh, kemudian (5) langkah kelima adalah menulis, mempresentasikan dan melaporkan temuan-temuan penelitian atau implikasiimplikasi teoritis dan kebijakan.

Sumber data netnografi dalam riset ini diambil dari kuesioner yang dikirimkan melalui surel kepada pemilik usaha dan telaah (review) para pelanggan Restoran X di zomato.com dan data diambil pada tanggal 21 September 2015. Jumlah penelaah atau pelanggan Restoran $\mathrm{X}$ yang menuliskan komentar pasca pembelian pada zomato.com berjumlah 998 telaah. Jumlah tersebut merupakan gabungan dari jumlah telaah untuk tujuh gerai Restoran X: Restoran X Pantai Indah Kapuk ada 351 telaah, Restoran X Casablanca: 260 telaah, Restoran X Ruko Green Lake Sunter: 77 telaah, Restoran X Grand Indonesia Mall: 100 telaah, Restoran X Central Park: 66 telaah, Restoran X Mall Taman Anggrek: 110 telaah, dan Restoran X Puri Indah Mall: 34 telaah. Lima dimensi orientasi pasar dari Hooley et al. (2012) pada Tabel 1 dijadikan landasan mengukur aras orientasi pasar perusahaan yang diteliti dalam penelitian ini.

\section{Hasil Penelitian}

Dari namanya orang yang belum tahu langsung berpikir bahwa Restoran $\mathrm{X}$ adalah restoran waralaba dari Jepang. Namun kenyataannya, walaupun memang menyediakan masakan khas Jepang, restoran ini dibangun sendiri (bukan waralaba) oleh anak bangsa. Menurut kesaksian pendirinya, awalnya ia pergi ke Jepang dan melihat kecenderungan restoran dessert di sana, kemudian itu menginspirasi mereka untuk memulai bisnis dessert di Indonesia. Menu dessert yang ditawarkan di restoran ini selain menggunakan istilah-istilah Jepang, juga menyajikannya dalam bentuk-bentuk yang unik. Restoran ini didirikan oleh seorang perempuan pengusaha muda, lulusan sarjana ilmu komunikasi, jurusan jurnalistik. Pada usia belum mencapai 30 tahun ia sudah mampu membangun bisnis ini dan sangat sukses, dan dalam waktu dua tahun, usaha yang dipimpinnya telah memperlebar pasarnya dengan membuka beberapa cabang di wilayah DKI Jakarta.

\section{Penilaian Internal Perusahaan}

Untuk mengetahui bagaimana penilaian internal perusahaan dari sudut orientasi pasar, peneliti mengirimkan kuesioner melalui surel kepada pemilik usaha. Kuesioner tersebut menentukan skor penilaian orientasi pasar dari sudut pandang internal perusahaan.

\section{Orientasi Pada Pelanggan}

Tabel I menunjukkan skor yang tinggi untuk CSO1, CSO2, CSO3, dan CSO5, namun skor yang rendah untuk CSO4. Hal tersebut menunjukkan bahwa perusahaan berorientasi pada pelanggan dengan selalu mengumpulkan secara teratur informasi mengenai kebutuhan dan permintaan pelanggan (CSO1), perusahaan memiliki tujuan dan kebijakan yang diarahkan untuk menciptakan kepuasan pelanggan (CSO2), dan tingkat kepuasan pelanggan tersebut dievaluasi secara teratur agar perusahaan 
dapat memperbaiki permasalahan apabila diperlukan (CSO3). Nilai skor CSO1, CSO2, dan $\mathrm{CSO} 3$ tersebut 5 (lima) atau sangat tinggi. Nilai skor CSO5 adalah 4 (empat) atau tinggi, yang menunjukkan bahwa perusahaan sudah mampu mengenali adanya perbedaan kelompok atau segmen dalam pasar dengan jenis kebutuhan yang berbeda namun mereka dapat menyesuaikan penawaran menurut kebutuhan pelanggan. Skor total 22 dari skor total tertinggi 25
(88\%) untuk dimensi orientasi pelanggan menunjukkan bahwa perusahaan sudah melakukan strategi yang berorientasi pada pelanggan. Satu butir indikator dari orientasi pelanggan yang harus ditingkatkan oleh perusahaan adalah CSO3, karena skor 3 menunjukkan bahwa perusahaan masih kurang berusaha dengan giat membangun keakraban dengan para pelanggan utama dan kelompok-kelompok pelanggan lainnya.

Tabel 2 - Skor Dimensi-Dimensi Orientasi Pasar

\begin{tabular}{|llll|}
\hline Customer Orientation (CSO) & Score & $\begin{array}{l}\text { Competitor Orientation } \\
\text { (CMO) }\end{array}$ & Score \\
CSO1 & 5 & CMO1 & 3 \\
CSO2 & 5 & CMO2 & 3 \\
CSO3 & 5 & CMO3 & 3 \\
CSO4 & 3 & CMO4 & 5 \\
CSO5 & 4 & Total & $14 / 70 \%$ \\
Total & $22 / 88 \%$ & & \\
Long-Term Perspectives (LTP) & Score & Interfuctional Coordination & Score \\
& & (IC) & 5 \\
LTP1 & 5 & IC1 & 5 \\
LTP2 & 2 & IC2 & 5 \\
LTP3 & 4 & IC3 & 5 \\
Total & $11 / 73 \%$ & IC4 & $20 / 100 \%$ \\
& & Total & \\
Organizational Culture (OC) & Score & & $\mathbf{8 7}$ \\
OC1 & 5 & SKOR TOTAL & \\
OC2 & 5 & & \\
OC3 & 5 & & \\
OC4 & 5 & & \\
Total & $50 / 100 \%$ & & \\
& & & \\
\hline
\end{tabular}

\section{Orientasi Pada Pesaing}

Tabel 2 menunjukkan capaian skor total 14 dari skor total tertinggi $20(70 \%)$ untuk dimensi orientasi pesaing menunjukkan bahwa perusahaan kurang memperhatikan aktivitas pesaing yang dapat membahayakan posisi kompetitif perusahaan dalam lingkungan persaingan dan perlu mengembangkan strategi berorientasi pada pesaing. Hasil penilaian menunjukkan bahwa skor CMO1, CMO2, dan CMO3 adalah 3 (tiga) dan itu menunjukkan bahwa perusahaan tidak secara teratur mengumpulkan informasi mengenai aktivitas pesaing, perusahaan juga tidak secara teratur membandingkan dirinya terhadap para pesaing utama, dan perusahaan tidak menanggapi dengan cepat tindakan-tindakan yang dilakukan oleh pesaing utama. Namun diferensiasi/keunikan produk dan layanan mereka yang menjadi faktor penting bagi para pelanggan sehingga mendapat perhatian yang sangat tinggi perusahaan, ditunjukkan dengan skor 5 .

\section{Perspektif Jangka Panjang}

Tabel 2 menunjukkan capaian skor total 11 dari skor total tertinggi 15 (73\%) menunjukkan perspektif jangka panjang aras sedangan. Perusahaan sudah lebih memprioritaskan pencapaian keunggulan pangsa pasar jangka panjang ketimbang laba jangka pendek (skor LTP1: 5). Pengambilan keputusan perusahaan sudah didasarkan pada pertimbangan jangka panjang ketimbang manfaat jangka pendek (skor LTP3: 4). 
Namun kelemahannya adalah bahwa perusahaan tidak menitik beratkan pada peningkatan kinerja pasar ketimbang meningkatkan efisiensi internal (skor LTP2: 2).

\section{Koordinasi antarfungsi}

Tabel 2 menunjukkan skor total 20 dari skor total tertinggi $20(100 \%)$ menunjukkan koordinasi antarfungsi sangat baik dalam perusahaan ini. Perusahaan telah melakukan hal-hal yang sangat penting dalam membangun koordinasi antarfungsi. Informasi tentang pelanggan disebarluaskan melalui komunikasi ke seluruh organisasi (skor IC1: 5). Masing-masing departemen dalam organisasi bekerja bersama dengan efektif untuk melayani kebutuhan pelanggan (skor IC2: 5). Ketegangan dan persaingan antar departemen tidak menghalangi proses pelayanan pelanggan secara efektif (skor IC3: 5). Organisasi perusahaan fleksibel demi mengejar peluang secara efektif ketimbang dibatasi secara hirarki/birokratis (skor IC4: 5).

\section{Budaya keorganisasian}

Tabel 2 menunjukkan skor total 20 dari skor total tertinggi 20 (100\%) menunjukkan perusahaan memiliki budaya keorganisasian yang baik. Pertama, semua karyawan sangat menyadari peran mereka dalam membantu untuk menciptakan kepuasan pelanggan (skor OC1: 5). Kedua, struktur imbalan/penghargaan karyawan sangat berkaitan erat dengan kinerja pasar eksternal dan kepuasan pelanggan (skor OC2: 5). Ketiga, para pimpinan senior di seluruh area fungsional telah sangat memberikan prioritas utama untuk menciptakan kepuasan pelanggan (skor OC3: 5). Keempat, rapatrapat yang dilakukan oleh para pimpinan senior sangat memprioritaskan untuk membahas hal-hal yang dapat mempengaruhi kepuasan pelanggan (skor OC4: 5).

\section{Orientasi-Pasar}

Tabel 2 menunjukkan skor total orientasi-pasar Restoran X adalah 87. Berdasarkan peringkat penafsiran skor total menyeluruh orientasi pasar: (1) Skor 80-100 menunjukkan orientasi-pasar aras tinggi, (2) Skor 60-80 menunjukkan orientasi-pasar sedangan, (3) Skor 40-60 yang menunjukkan perlu mengembangkan orientasi-pasar, dan (4) Skor 20-40 yang menunjukkan masalah besar masih menghadang pengembangan orientasi-pasar, maka skor total 87 menunjukkan perusahaan sudah melakukan orientasi pasar aras tinggi (high level of market orientation) (Hooley et al., 2012).

\section{Penilaian Konsumen dalam Komunitas Maya}

Setelah mengumpulkan data dari 998 telaah, membacanya, menganalisis dan membuat interpretasi, maka studi ini melihat strategi berbasis orientasi pasar dapat menjadi strategi yang harus dikembangkan oleh perusahaan.

\section{Strategi Berbasis Orientasi Pasar}

Mengacu dimensi-dimensi orientasi pasar yang diusulkan oleh Hooley et al. (2012:8), beberapa hal yang harus menjadi perhatian perusahaan ini dalam membangun strategi berorientasi pada pasar, yang mana dasar dorongan untuk membangun strategi tersebut didasarkan pada suara-suara konsumen. Sebagian besar konsumen yang meninggalkan telaah mereka pasca pembelian pada zomato.com menunjukkan kepuasan mereka pada produk perusahaan, dan bahkan kebanyakan mereka telah berkunjung berkali-kali yang menunjukkan kesetiaan mereka. Komentar-komentar yang diambil secara acak seperti berikut ini mewarnai telaah untuk semua gerai Restoran $\mathrm{X}$ yang menggambarkan bagaimana kinerja perusahaan tersebut.

\footnotetext{
"Siapa sih yang nga tau restoran $\mathrm{X}$ ? restoran $\mathrm{X}$ pertama kali buka (kalo nga salah) di pantai indah kapuk dan meskipun uda buka cabang dimana2, restoran $\mathrm{X}$ tetap rame loh sampe hari ini. the star of restoran $\mathrm{X}$ pastinya nutella bomb-nya dong! (my favorite kakigori number 5) ada juga es serut yg bentuknya beruang lucu2 dan buta ramen, rasa mie-nya mirip indomie tapi with egg and daging gitu rasanya jd lebih mantep lagi, dan ada level pedasnya juga loh (level 1-30 kalo nga salah)" - Karen
} 
Haryono, post on <zomato.com> 8/9/2015 (telaah Restoran X Pantai Indah Kapuk).

"Restoran $\mathrm{X}$ is me and my friends favorite dessert place. It's near our office. And all of their menus are good and value for money. My favorite is boo! Kakigori! Es seruuuut" Meilia Seanty Riselina, post on <zomato.com> 7/9/2015 (telaah Restoran X Grand Indonesia).

"Tempatnya memang tidak luas jadi sering waiting list. Dekorasinya bagus. Menu2nya enak dan ada yang bentuknya lucu. Pelayanan cepat dan ramah" -- Indah Charniessa, post on <zomato.com> 6/9/2015 (telaah Restoran X Mall Taman Anggrek).

Waktu itu iseng nyobain yg di puri ternyata tempatnya kecil dan selalu ramai. Gue pesen mixed puding+kitkat+sliced almond+mochi,dan yg ngga ketinggalan nutella bombnya. Kalo kesini harus rela waiting list apa lg kalo weekend" -- Luna Isyaira, post on <zomato.com> 5/9/2015 (telaah Restoran X Puri Indah Mall).

Dateng kesini pas malam minggu dan waiting list. Tapi pesanannya cepet diantar.. Eskrim matcha nya recommended. Menunya dessertnya Mirip dgn hongtang. Recommended buat dicoba - Dinana, post on <zomato.com> 10/9/2015 (telaah Restoran X Central Park).

"Sama kayak semua outlet Restoran X yang ada di dunia ini, outlet ini selalu penuh pengunjung, waiting list yang super panjang gak bikin orang-orang menyerah. Dulu pas awal-awal buka, kalo makan di ikkudo ichi bisa pesen Restoran X juga, sekarang udah gak bisa, harus take away (yang menurut saya porsinya jadi lebih sedikit). Pelayanannya sih cepet, rasa makanan dan terutama my favorite nutella bomb nya sama kayak yang di PIK, everything is good! Yang minus dari Restoran X outlet ini sih karena tempatnya terlalu kecil dan terbuka jadi bisa diliatin sama pengunjung waiting list, kalo makanan udah mau abis pasti diliatin, risih, habis makan gabisa ngobrol2 dulu" Alenda Putriarni, post on <zomato.com> Agustus 2015 (telaah Restoran X Casablanca).

Hampir selalu ngantri kalo ke sini tapi tetap aja dibelain demi istri.. Yang pasti selalu dipesen itu Buta Ramen dan Nutella Bom nya.. Kalau suka makanan yang pedas, Buta Ramennya ada pilihan tingkat pedasnya.. Bisa take away juga sih kalo males nunggu waiting list.." Picky Eater Jkt, post on <zomato.com> Agustus 2015 (telaah Restoran X Green Lake Sunter).
Namun demikian perusahaan tidak boleh terlalu puas diri dan tidak memperhatikan para pelanggan yang memberikan evaluasi demi perbaikan kinerja perusahaan. Oleh sebab itu, mendengarkan keluhan pelanggan yang ditanggapi secara positif juga dapat meningkatkan kinerja perusahan. Strategi berorientasi pada pelanggan, pesaing, fokus pada keunggulan jangka panjang dan membangun koordinasi antarfungsional dibutuhkan dalam meningkatkan kinerja perusahaan.

\section{Berorientasi pada Pelanggan}

Kepuasan pelanggan harus menjadi prioritas dalam membangun strategi orientasi pasar. Informasi tentang kebutuhan dan permintaan pelanggan harus dikumpulkan secara teratur. Dengan demikian peningkatan kualitas layanan menjadi hal yang sangat penting dalam membangun strategi yang berorientasi pada pelanggan. Demikian juga halnya dengan apa yang harus dilakukan oleh Restoran X. Perusahaan harus aktif untuk mengevaluasi keluhan pelanggan demi meningkatkan layanan dan menjamin kepuasan pelanggan. Seringkali pelanggan tidak secara langsung memberikan kritiknya, namun mereka lebih nyaman menuangkan ketidakpuasan mereka misalnya pada forumforum di Internet, dan oleh sebab itu perusahaan harus menyediakan waktu untuk menelusuri bagaimana kesan para pelanggan yang dapat ditemukan pada forum-forum tersebut. Misalnya pada forum telaah di zomato.com ada banyak pelanggan yang dengan terbuka dan nyaman mengungkapkan kepuasan sekaligus keluhan mereka pada perusahaan. Berikut ini adalah beberapa kutipan yang diambil dari forum tersebut.

\footnotetext{
"Yummy dessert. We had the restoran X dessert and the mini parfait. Both were delicious and good portion. Service can be a lot better. It took forever to get the bill. It took even longer to get our credit card back. We had to ask 4 different staff. And the place wasn't even full!" - Djunadi Satrio, post on <zomato.com> 21/9/2015.
} 
Dari kutipan tersebut pelanggan memberikan baik pujian maupun keluhan. Pelanggan puas dengan kualitas dessert, namun mengeluh atas kualitas layanan. Pelanggan menilai dessert yang ia nikmati lezat dan porsinya juga cukup. Namun ia mengharapkan agar pelayanan dapat dilakukan lebih baik. Ia juga mengeluhkan staf yang melayani tagihan atau pembayaran dengan kartu kredit. Ia menilai bahwa staf tidak memiliki pengetahuan dan kemampuan yang baik dengan memberikan layanan transaksi dengan kertu kredit. Pelanggan menilai bahwa tidak ada staf khusus yang memang mampu untuk memberikan pelayanan tersebut, karena bahkan perlu empat orang yang berbeda untuk memberikan layanan tersebut. Jika perusahaan benar-benar ingin membangun strategi bisnis yang berorientasi pada pelanggan, selain menjaga kualitas produk dan rasa, seharusnya dapat melihat bahwa kualitas layanan menjadi perhatian yang sangat penting untuk ditingkatkan dan dievaluasi secara terus menerus. Perhatikan evaluasi yang sama yang diberikan oleh Astrid Belladina Victoria berikut ini:

\footnotetext{
"Kind of must-stop-dessert place in kokas. The place is always full! The desserts are presented cutely. Kakigori boo! was so cuteee, I can't even ajskaoejejndnd and the portion was a lot even for two. The yakult drink was not my thing. Evenso, the service was bad. Waiters are not responsive and even if its hectic, I saw some of their chit chatting like there was nothing to do. Still willing to come back though and taste their nutella bomb!!" - Astrid Belladina Victoria, post on <zomato.com> Juni 2015.
}

Astrid Belladina Victoria tidak puas dengan pelayanan yang diterimanya. Ia menilai pelayanan perusahaan buruk, para pramusaji tidak responsif dan bahkan berisik, mengobrol tanpa melakukan apapun. Ketidakpuasan pelayanan juga disampaikan oleh - Putri Ata

\footnotetext{
"Kalo ke sini pesennya ya matcha yg bentuknya entah panda entah anjing itu yg penting lucukkkkkkk hehehehe well, bagus
}

enak2 kok makanannya hanya saja tempat yg begitu kecil dan pengungjung yg begitu antusias jadinya gabisa terlalu memuaskan pelayanannya jika datang dengan membawa rombongan" - Putri Ata, post on <zomato.com> Juni 2015

Membuat sistem pelayanan yang terkoordinasi dengan baik juga sangatlah penting untuk menjamin kepuasan pelanggan. Pelanggan yang menunggu makanan terlalu lama akan menyebabkan kebosanan dan bahkan mungkin kejengkelan. Apalagi dalam kondisi lapar. Kutipan berikut ini menunjukkan kondisi tersebut.

\footnotetext{
"Quite delicious, but not worthy for the price. Very poor service. I waited for about 1 hours to get one of the dessert, while other desserts are already served" - Shiina Lee, post on <zomato.com> Juni 2015.
}

Shiina Lee mengekspresikan ketidakpuasannya terhadap layanan yang diberikan dan melihat kurangnya koordinasi pemberian layanan. Ia merasa jengkel oleh karena harus menunggu satu pesanan dessert sampai satu jam, yang mana ia juga melihat bahwa justru pesanan dari pelanggan lain yang lebih belakangan dilayani lebih dulu. Strategi yang berorientasi pada pelanggan harus memperhatikan koordinasi layanan yang baik dan secara runtut menampilkan layanan yang baik, bahkan walaupun pelanggan hanya membeli dalam volume kecil, misalnya hanya memesan satu produk yang ditawarkan.

\section{Berorientasi pada Pesaing}

Mengumpulkan informasi tentang pesaing, membandingkan diri terhadap pesaing utama, bertindak cepat terhadap tindakan-tindakan yang dilakukan pesaing, menitik beratkan pada keunikan merupakan indikator dari perusahaan yang menerapkan strategi orientasi pasar, khususnya pada dimensi orientasi pesaing. Hal tersebut menjadi penting karena pelanggan juga memiliki kecenderungan untuk membandingbandingkan produk yang ditawarkan perusahaan dengan yang ditawarkan oleh 
perusahaan pesaing. Perhatikan kutipan berikut ini:

\begin{abstract}
"Awal nya kan yg happening ice green tea nya yaaa... Itu juga enak koook, cuma karna udh banyak tempat dessert serupa menyajikan hal yg sama jadi kaya nda ada bedanya ya. Cuma ttp harus di cobain biar compare sama tempat dessert yg lain hehe, nutella bomb juga kudu di coba, wajib! Temen-temen gue yg sebelumnya belum pernah ke sini \& penasaran sama ice green tea dan jelly dkk begitu coba nutella bomb, malah lbh prefer ke nutella bomb \& they said next time they will order nutella bomb aja gitu" - Hagina, post on <zomato.com> Juli 2015.
\end{abstract}

"Pernah mengunjungi restoran X Central Park dan Grand Indonesia. Menurutku restoran X standard saja, mungking karena memang $1 \mathrm{~g}$ hype bgt seingga banyak yang kesini. Overall mirip2 dengan asian desserts lainnya, paling plattingnya dibikin lebih unik dan lucu. Pernah coba mie nya dan menurut ku itu hanya mie ramen instan saja, agak kurang worthit untuk harga hampir skitar 45k (incl tax and service)" - Clarie, post on <zomato.com> Maret 2015.

"Awal-awal buka di kokas antrinya ga nahan boo. Dibanding tetangga sejenisnya, sebut saja bola hitam, gue lebih suka dessert di sini. Topping japanese dessertnya heboh. Matchanya endes. Overall 4 of 5" - Ria Febriyani, post on <zomato.com> April 2015.

Kutipan-kutipan di atas menunjukkan bahwa sebagian pelanggan cenderung membandingkan produk yang ditawarkan perusahaan terhadap produk-produk sejenis yang di tawarkan oleh perusahaanperusahaan pesaing. Pelanggan menilai kualitas produk Restoran X baik, ia berkata enak, namun ia juga berkomentar bahwa produk yang ditawarkan oleh perusahaanperusahaan yang menjual produk serupa juga tidak kalah enak. Pernyataan tersebut menunjukkan bahwa pelanggan belum melihat pembeda atau keistimewaan produk Restoran $\mathrm{X}$ dibandingkan dengan produk pesaing. Menitik-beratkan pada keunikan menjadi salah satu indikator strategi berorientasi pesaing yang menjadi dimensi orientasi pasar. Dengan membaca komentar Hagina, Clarie, dan Ria Febriyani tersebut, perusahaan harus membuat evaluasi dengan membandingkan keunikan produk yang ditawarkan dengan produk-produk yang ditawarkan oleh pesaing, yaitu perusahaan yang menawarkan produk-produk dessert serupa.

\section{Fokus pada Keunggulan Jangka Panjang}

Untuk perusahaan yang menjual produk dan jasa seperti Restoran X, keruntutan kualitas produk dan layanan harus selalu diperhatikan dan dievaluasi. Dalam strategi orientasi pasar yang fokus pada keunggulan jangka panjang, menjaga keruntutan kualitas produk akan menciptakan kepuasan konsumen dan keuntungan jangka panjang. Hal tersebut dapat menciptakan keunggulan bersaing lestari (sustainable competitive advantage). Kutipan berikut ini menunjukkan harapan pelanggan terhadap keruntutan kualitas produk yang akan menjamin pelanggan untuk datang kembali di lain kesempatan.

\footnotetext{
"Udh bbrp kali dtg ke Restoran X dr awal buka sampai skrg di cabang mana aja hehehe, dan selalu pesan buta ramennya dgn cabe level 25 dan selalu enak mantap, $\mathrm{cm}$ trkdg dagingnya ad bau krg sedap, overall enak sih dan favorit" Stephany Lie, post on <zomato.com> 10/9/2015.
}

Dari kutipan tersebut pelanggan memberikan evaluasi tentang keruntutan kualitas produk yang ditawarkan oleh perusahaan. Pelanggan menunjukkan keruntutannya dalam memilih salah satu jenis produk yang ditawarkan perusahaan, yaitu "buta ramen level 25", namun kemudian ia menilai kualitas produk tersebut tidak runtut. Pelanggan mengatakan bahwa "terkadang" dagingnya berbau kurang sedap. Namun untungnya pelanggan masih menilai dari segi rasa masih enak dan produk tersebut masih menjadi kesukaanya. Namun demikian perusahaan tetap harus melakukan evaluasi keruntutan kualitas bahan baku dan produknya, karena reaksi pelanggan lain bisa jadi tidak sama. Mungkin saja mereka kecewa atas ketidak-runtutan kualitas produk tersebut dan tidak berniat untuk kembali setia pada produk perusahaan. 
Keruntutan pemberian kualitas pelayanan juga harus menjadi perhatian perusahaan untuk membangun keunggulan kompetitif jangka panjang. Perhatikan kutipan-kutipan telaah di bawah ini:

"Ini dessert place kan booming banget. Tiap lewat selalu ada antrian, jadi penasaran aja coba \& emang tertarik sama bentuknya yang lucu2. Akhirnya saya \& partner memutuskan untuk mengunjungi gerai Restoran X di Central Park. First impression, staff kurang semangat dalam melayani pengunjung. Mungkin udah lelah karena ramai? Kita dapet tempat duduk yang lumayan bagus, deket jendela. Jadi bisa ngeliat luar \& kebetulan menjelang maghrib. Lumayan, ala2 sunset. Sayangnya bagian itu cenderung panas. Mungkin ACnya kurang?" Nadia, post on <zomato.com>5/9/2015.

"Kami datang di hari Minggu pagi \& kebetulan kami pengunjung pertama. Surprise, surprise. Setelah mengalami pelayanan staff yang kurang di gerai Central Park, agak kaget juga dengan tingkat keramahan \& profesionalitas waiter yang melayani meja kami. Tempat juga masih terkesan bersih" - Nadia, post on <zomato.com>14/9/2015.

Just simple review. Nice place, good ambience, warmful waiter / waitress, and for sure yummy in my taste bud. The service is good, not too long waiting my order, maybe it coz not too much customer this day - Arnold David Teddy, post on <zomato.com> 16/9/2015.

"I went here because im craving their buta naked ramen, and kakigori with nutella bomb. Luckily today ga terlalu rame, dan langsung dapet tempat. Dan pelayanannya juga baik, dan cepat" - Chrisshania Callista, post on <zomato.com>16/9/2015.

Went here at sunday noon, the place was crowded and i had to wait. 5 minutes later i got my seat and ordered strawberry boo kakigori, restoran $\mathrm{X}$ dessert the most complete one, nutella ball and french fries. They all tasted good. The foods also came fast. The service was corteous and helpul - Olivia, post on <zomato.com> 6/9/2015.

Dari kutipan-kutipan telaah pelanggan di atas menunjukkan ketidak-runtutan staf perusahaan dalam menunjukkan kualitas layanan. Nadia merasa tidak puas dengan pelayanan di gerai Central Park, dan ketidakpuasan tersebut ia tuliskan dalam telaahnya untuk Restoran X Central Park pada tanggal 5 September 2015. Kemudian ketidakpuasan tersebut ia ungkapkan kembali pada telaahnya untuk Restoran X PIK pada tanggal 14 September 2015. Intinya pertama, Nadia menilai layanan gerai di Central Park tidak memuaskan, namun layanan di gerai PIK memuaskan. Kedua, Nadia menilai bahwa staf yang melayani kurang semangat dalam melayani pengunjung dan Nadia berasumsi mungkin karena mereka lelah dalam kondisi gerai yang ramai pengunjung. Kemudian di gerai yang sama, Restoran $\mathrm{X}$ Central Park, Armold David Teddy menerima pelayanan yang baik dan ia berasumsi beruntung hari itu gerai sedang dalam keadaan tidak terlalu ramai. Demikian juga tanggapan dari Olivia yang puas dengan layanan yang diterimanya pada saat berkunjung di gerai Central Park, namun bedanya pada waktu itu kondisi gerai sedang ramai pengunjung.

Pesan yang diperoleh dari beberapa telaah tersebut, perusahaan harus peka bahwa demi mempertahankan keunggulan kompetitif berkelanjutan atau strategi fokus jangka panjang, keruntutan baik dalam menjaga kualitas produk maupun kualitas layanan menjadi sangat penting bagi gerai boga.

\section{Membangun Koordinasi Antarfungsi}

Dalam membangun strategi yang berorientasi pasar, khususnya pada dimensi koordinasi antarfungsi dalam organisasi, standard layanan yang sama tingginya harus diberikan oleh seluruh departemen, atau pun cabang-cabang perusahaan. Misalnya, untuk kasus Restoran X, pelanggan berikut ini menilai adanya perbedaan standard kualitas layanan staf yang sangat mendasar antara cabang perusahaan di Central Park dengan Restoran X di Pantai Indah Kapuk.

\footnotetext{
"Kami datang di hari Minggu pagi \& kebetulan kami pengunjung pertama. Surprise, surprise. Setelah mengalami pelayanan staff yang kurang di gerai Central Park, agak kaget juga dengan tingkat keramahan \& profesionalitas waiter
} 
yang melayani meja kami. Tempat juga masih terkesan bersih" - Nadia, post on <zomato.com> 14/9/2016.

Pelanggan menilai ketidakpuasannya terhadap layanan yang diberikan di gerai Central Park, namun kemudian terkejut karena layanan yang diterimanya di Pantai Indah Kapuk sangat memuaskan. Informasi pelanggan seperti ini seharusnya dapat ditanggapi dengan menyebarluaskannya ke seluruh organisasi, termasuk di setiap cabang atau gerai perusahaan. Standarisasi layanan dari staf restoran di semua gerai merupakan harapan dari pelanggan, oleh sebab itu menyebarluaskan informasi kepuasan dan keluhan pelanggan di satu gerai dibandingkan dengan gerai lainnya harus dievaluasi dan sebarluaskan ke semua gerai yang ada.

Kalau Nadia menilai layanan staf di gerai Central Park kurang, sebaliknya pada telaah untuk gerai Central Park di zomato.com, Arnold David Teddy menilai layanan pada gerai tersebut baik.

Just simple review. Nice place, good ambience, warmful waiter / waitress, and for sure yummy in my taste bud. The service is good, not too long waiting my order, maybe it coz not too much customer this day - Arnold David Teddy, post on <zomato.com>16/9/2016.

Pada kesempatan yang lain Nadia juga memberikan komentarnya untuk telaah gerai Central Park. Nadia menilai layanan yang kurang memuaskan di gerai Central Park bisa jadi disebabkan oleh karena staf lelah karena ramainya pengunjung, sehingga mereka kurang terlihat semangat dalam memberikan layanan. Nadia berkata demikian,

"Ini dessert place kan booming banget. Tiap lewat selalu ada antrian, jadi penasaran aja coba \& emang tertarik sama bentuknya yang lucu2. Akhirnya saya \& partner memutuskan untuk mengunjungi gerai Restoran X di Central Park. First impression, staff kurang semangat dalam melayani pengunjung. Mungkin udah lelah karena ramai? Kita dapet tempat duduk yang lumayan bagus, deket jendela. Jadi bisa ngeliat luar \& kebetulan menjelang maghrib.
Lumayan, ala2 sunset. Sayangnya bagian itu cenderung panas. Mungkin ACnya kurang?" Nadia, post on <zomato.com> 5/9/2016.

Keruntutan dalam memberikan layanan harus dipertahankan, karena pada waktu pengunjung restoran yang begitu ramai, bahkan sampai ada para pelanggan yang rela daftar tunggu, para pelayan restoran bahkan sering tidak sempat istirahat. Tekanan kerja tersebut bisa saja menurunkan keramahan atau fokus staf dalam memberikan layanan ketika kondisi restoran sedang ramai pengunjung. Pada waktu Arnold David Teddy berkunjung ke Restoran $\mathrm{X}$, ia sendiri mengatakan bahwa tidak terlalu banyak pelanggan yang ada di sana pada hari itu. Ia puas dengan layanan yang diberikan dan menilai layanannya baik karena ia tidak terlalu lama menunggu pesanannya, dan ia juga memberi alasan mungkin itu karena tidak terlalu banyak pelanggan hari itu. Pada hari yang sama Chrisshania Callista juga memberikan telaah pada zomato.com untuk gerai Central Park, dan mengatakan bahwa ia puas dalam kunjungannya di gerai Central Park pada kondisi gerai yang tidak terlalu ramai pengunjung. Callista berkata,

\footnotetext{
"I went here because im craving their buta naked ramen, and kakigori with nutella bomb. Luckily today ga terlalu rame, dan langsung dapet tempat. Dan pelayanannya juga baik, dan cepat" - Chrisshania Callista, post on <zomato.com> 16/9/2016.
}

Memang benar bahwa kondisi tidak selalu sama setiap waktu dalam bisnis boga, terkadang ramai dan ada kalanya sepi pengunjung. Namun oleh karena yang diharapkan perusahaan selalu ramai, maka perusahaan harus siap untuk memberikan layanan terbaik pada saat ramai pengunjung. Jika layanan staf baik pada waktu kondisi sepi, namun menjadi mengecewakan ketika ramai pengunjung, penambahan tenaga pemberi layanan adalah keputusan yang bijak. 


\section{Simpulan dan Implikasi Manajerial}

Hasil penilaian internal perusahaan melalui kuesioner ditemukan kelemahankelemahan yang masih perlu dikembangkan perusahaan dalam penerapan orientasi pasar, yaitu: Pertama, orientasi pada pelanggan. Perusahaan harus berusaha dengan lebih giat lagi untuk membangun keakraban dengan pelanggan utama maupun kelompokkelompok pelanggan lainnya, karena hasil penilaian menunjukkan skor CSO4 rendah. Kedua, perspektif jangka panjang. Perusahaan harus lebih menitik beratkan lagi pada peningkatan kinerja pasar ketimbang meningkatkan efisiensi internal, karena hasil penilaian menunjukkan skor LTP2 rendah. Ketiga, orientasi pesaing. Dimensi ini yang paling harus mendapatkan perhatian perusahaan, karena perusahaan memiliki orientasi pesaing yang rendah. Hal tersebut ditunjukkan oleh rendahnya skor CMO1, yang mana informasi mengenai aktivitas pesaing tidak dikumpulkan secara teratur oleh perusahaan. Skor CMO2 juga rendah, yang mana perusahaan tidak secara teratur membandingkan dirinya terhadap pesaing utamanya. Kemudian skor CMO3 juga rendah, yang mana perusahaan kurang menanggapi dengan cepat tindakan-tindakan yang dilakukan oleh pesaing utama.

Berdasarkan pendekatan netnografi terhadap 998 telaah pelanggan perusahaan pasca pembelian di zomato.com, dapat disimpulkan: Pertama, evaluasi atau telaah pelanggan dalam komunitas maya patut menjadi data informasi yang penting bagi perusahaan. Apa yang mereka katakan atau percakapan lebih alami tanpa adanya tekanan instruktif atau merasa tidak nyaman yang dilatarbelakangi oleh budaya Timur. Alamiah masukan atau komentar mereka menjadi data informasi yang sangat penting dalam peningkatan kinerja perusahaan. Kedua, dari pembahasan hasil studi netnografi di atas dapat dilihat bahwa pengembangan orientasi pasar sebagai basis strategi bisnis diperlukan oleh perusahaan. Masukan dari para pelanggan merupakan harapan mereka bagi perusahaan. Ketiga, dimensi strategi orientasi pasar yang perlu dikembangkan oleh perusahaan adalah strategi berorientasi pada pelanggan dan pesaing, fokus pada keunggulan jangka panjang dan membangun koordinasi antarfungsi dibutuhkan dalam meningkatkan kinerja perusahaan. Harapan pelanggan agar perusahaan dapat meningkatkan kualitas produk dan layanan demi kepuasan pelanggan sebagai strategi yang berorientasi pada pelanggan harus benar-benar menjadi perhatian perusahaan. Oleh karena sebagian pelanggan cenderung membandingkan produk dan layanan perusahaan terhadap produk dan layanan perusahaan lain, maka strategi berorientasi pesaing juga perlu dikembangkan. Kemudian membangun keruntutan kualitas produk dan layanan dapat dilihat sebagai dasar keunggulan bersaing lestari. Perusahaan ini memiliki sedikitnya tujuh gerai di tujuh tempat yang berbeda, dan beberapa pelanggan juga membandingkan kualitas pelayanan antara satu gerai dengan gerai lainnya, maka membangun koordinasi antarfungsi dan antar gerai untuk membangun standard produk dan layanan yang sama baiknya perlu dikembangkan juga oleh perusahaan. Perusahaan perlu membuat standar operasional prosedur (SOP), pelatihan karyawan, penambahan jumlah karyawan dan rotasi.

\section{Daftar Pustaka}

Carbonell, P. and Escudero, A. I. R. 2010. The Effect of Market Orientation on Innovation Speed and New Product Performance. Journal of Business \& Innovation Marketing, 25/7, pp. 501-513

Carey, J. W. 1989. Communication as Culture: Essays on Media and Society. Boston, MA: Unwin-Hyman.

Fang, S-R., Chang, E., Ou, C-C. and Chou, C-H. 2014. Internal Market Orientation, Market Capabilities and Learning Orientation. European Journal of Marketing, Vol. 48 Iss 1/2 pp. 170 - 192 
Hooley, G., Piercy, N. F., and Nicoulaud, B. Marketing Strategy \& Competitive Positioning. Fifth Edition. Prenctice Hall.

Jones, S. G. 1995. Understanding Community in the Information Age. in Cybersociety: Computer-mediated Communication and Community, ed. Stephen G. Jones, Thousand Oaks, CA: Sage, 10-35.

Julian, C. C., Mohamad, O., Ahmed, Z. U. and Sefnedi, S. 2013. The Market Orientation-Performance Relationship: The Empirical Link in Export Ventures. Thunderbird International Business Review, Vol. 56 (1): 97-110.

Kara, A., Spillan, J. E. and DeShields, O. W. 2005. The Effect of a Market Orientation on Business Performance: A Study of SmallSized Service Retailers Using MARKOR Scale. Journal of Small Business Management, 43(2), pp. 105-118.

Kohli, A. K. and B. J. Jaworski. 1990. Market Orientation: The Construct, Research Propositions, and Managerial Implications, Journal of Marketing, Vol. 54 No. 2, pp. 118.

Kozinets, R. V. 1998. On Netnography: Initial Reflections on Consumer Research Investigations of Cyberculture. In Advances in Consumer Research, Volume 25, ed., Joseph Alba and Wesley Hutchinson, Provo, UT: Association for Consumer Research, 366-371.

Kozinets, R. V. 2010. Netnography. Doing Ethnographic Research Online. Thousand Oaks, CA: Sage Publications.

Kozinets, R. V. 2002. The Field Behind the Screen: Using Netnography for Marketing Research in Online Communities. Journal of Marketing Research, 39 (February), 61-72.
Matsuno, K., Mentzer, J. T. and Rentz, J. O. 2000. A Refinement and Validation of the MARKOR Scale. Journal of Academy of Marketing Science, Vol. 28 No. 4, pp. 52739.

Maulana, A. E. 2009. Consumer Insights via Ethnography. Esensi Erlangga Group. Jakarta.

Muniz, A. and O'Guinn, T. C. 2001. Brand Community. Journal of Consumer Research.

Narver, J. C. and Slater, S. F. 1990. The Effect of a Market Orientation on Business Profitability. Journal of Marketing: 20-35.

Nguyen, P. M. C. 2013. The New Contribution of Netnography in New Product Development. Master's Thesis in International Business, University of Turky.

O'Sullivan, D. and Butler, P. 2009. Market orientation and enterprise policy. European Journal of Marketing, Vol. 43 Iss 11/12 pp. 1349 - 1364

Perreault, W. D., and McCarthy, J. E. 2002. Basic Marketing: A Global Approach, $14^{\text {th }}$ ed. Homewood, IL: McGraw Hill-Irwin.

Pulendran, S., Speed, R., Widing II, R. E. 2003. Marketing Planning, Market Orientation and Business Performance. European Journal of Marketing, Vol. 37 Iss $3 / 4$ pp. $476-497$ 